\title{
A Mixed Element Method for the Desorption-Diffusion-Seepage Model of Gas Flow in Deformable Coalbed Methane Reservoirs
}

\author{
Lei Yang \\ School of Mathematics, Shandong University, Jinan 250100, China \\ Correspondence should be addressed to Lei Yang; yanglei1021@126.com
}

Received 5 July 2014; Revised 1 September 2014; Accepted 2 September 2014; Published 28 September 2014

Academic Editor: Kim M. Liew

Copyright (C) 2014 Lei Yang. This is an open access article distributed under the Creative Commons Attribution License, which permits unrestricted use, distribution, and reproduction in any medium, provided the original work is properly cited.

We present a desorption-diffusion-seepage model for the gas flow problem in deformable coalbed methane reservoirs. Effects of fracture systems deformation on permeability have been considered in the proposed model. A mixed finite element method is introduced to solve the gas flow model, in which the coalbed gas pressure and velocity can be approximated simultaneously. Numerical experiments using the lowest order Raviart-Thomas $\left(\mathrm{RT}_{0}\right)$ mixed element are carried out to describe the dynamic characteristics of gas pressure, velocity, and concentration. Error estimate results indicate that approximation solutions could achieve first-order convergence rates.

\section{Introduction}

Coalbed methane (CBM) is an abundant, low cost energy source, which has become a viable alternative source to conventional fuel. CBM reservoirs are dual porosity systems consisting of coal matrix and fracture network [1]. In CBM reservoirs, most of coalbed gas is stored in the coal matrix as adsorbed gas, and only a small amount is stored in fracture systems as free gas. Comparing with conventional natural gas reservoirs, the effect of fracture systems deformation on permeability is significant in CBM reservoirs [2-4]. Meanwhile, the gas flow in fracture systems is driven not only by pressure field but also by gas concentration field $[5,6]$, so we need to consider Darcy seepage and Fick diffusion simultaneously in multifield. As coalbed gas is released from CBM reservoirs, fracture system pressure reduces, resulting in gas diffusion in the coal matrix and gas desorption from coal matrix surface to fracture systems. Therefore, the gas flow process in CBM reservoirs includes gas desorptiondiffusion in coal matrix and gas seepage in fracture systems [7-10]. Usually, the fracture systems are considered as the gas flow passage and the coal matrix is treated as the source for fracture systems.

Based on the above understandings about coalbed gas flow mechanism, a series of conventional mathematical and numerical models $[5,6,11,12]$ have been developed, obtaining some useful computational and simulation results. Young [11] presented a computer model for CBM reservoirs to determine key data and to describe the variability in CBM reservoir properties. Unsal et al. [12] proposed a numerical model for multiphase flow in CBM reservoirs using a fracture-only model. Thararoop et al. $[5,6]$ developed a compositional dual porosity, dual permeability CBM numerical model to describe the pressure and concentration dynamic behaviors. Nevertheless, the existing CBM numerical simulation methods are based on finite difference scheme and mainly focus on gas pressure and concentration, ignoring gas flow velocity.

Mixed finite element method was initially introduced by engineers [13] in the 1960s and has been applied to many areas such as solid and fluid mechanics, which could approximate both vector variable (e.g., the fluid velocity) and scalar variable (e.g., the pressure) simultaneously and give a high order approximation of both variables. Comparing with the standard finite element method only employing a single finite element space, mixed finite element method need construct two different finite element spaces. Raviart and Thomas [14] introduced the first family of mixed finite element spaces for second-order elliptic problems. Nedelec [15] extended these spaces to three-dimensional problems. Then, Brezzi et al. $[16,17]$ and Chen and Douglas [18] presented many mixed finite element spaces. 
In addition, the study about numerical method and numerical analysis for fluid flow problems in porous media has been a research hotspot for the past decades [19-24], due to its wide applications in various engineering areas. Douglas et al. [19-21] have done a lot of useful work for the fluid flow problem in porous media. For the incompressible miscible displacement problem in porous media, Wang [22] introduced ELLAM-MFEM to solve equation of the problem. A component-based Eulerian-Lagrangian method [23] was used to treat the multicomponent, multiphase flow problem in porous media. Li and Sun [24] presented an unconditional convergence Galerkin-mixed element approximation for the incompressible miscible flow problem. However, until now, we have not found any paper considering mixed element approximation scheme for the gas flow problem in deformable CBM reservoirs.

The aim of this paper is to study the gas flow problem in deformable CBM reservoirs using mixed element method. For this purpose, we introduce a mixed finite element method to approximate the coalbed gas pressure and velocity simultaneously. Another objective of this paper is to carry out some numerical experiments using the lowest order RaviartThomas mixed element, so as to show the convergence rate of the mixed element approximation method, and to analyze coalbed gas flow characteristics.

This paper is organized as follows. In Section 2, considering the effects of fracture system deformation, we present a desorption-diffusion-seepage model of gas flow in deformable CBM reservoirs for the two-dimensional problem. In Section 3 we introduce a mixed finite element approximation scheme for the coalbed gas flow model. In Section 4 numerical experiments using the lowest order Raviart-Thomas $\left(\mathrm{RT}_{0}\right)$ mixed element are carried out.

\section{Coalbed Gas Flow Problem in Deformable CBM Reservoirs}

In this section, considering the pressure dependence of permeability and porosity, we derive a mathematical model for the gas flow problem in deformable CBM reservoirs.

\subsection{Basic Assumptions and Gas State Descriptions}

(i) CBM reservoirs are treated as dual porosity systems consisting of coal matrix and fracture network.

(ii) CBM reservoirs are isothermal. When pressure variation is not significant, we can assume the gas viscosity is constant under isothermal conditions [25].

(iii) The gas diffusion process in the coal matrix is pseudostatic and described by Fick's first diffusion law.

(iv) Gas absorption/adsorption is described by Langmuir adsorption isotherm.

The equation of real gas state is

$$
p V=n Z R T=\frac{m}{M} Z R T
$$

where $p$ is the gas pressure, $V$ is the gas volume, $n$ is the amount of substance, $T$ is the gas temperature, $m$ is the gas mass, $M$ is the gas molar mass, $Z$ is the gas deviation factor, and $R$ is the universal gas constant. From (1) the gas density $\rho$ can be written as

$$
\rho=\frac{m}{V}=\frac{p M}{Z R T} .
$$

According to the Langmuir isotherm and the state equation of real gas, the adsorbed gas concentration $C_{m}$ in coal matrix and free gas concentration $C_{f}$ in fracture systems can be written, respectively, as

$$
C_{m}\left(p_{m}\right)=\frac{C_{L} p_{m}}{p_{L}+p_{m}}, \quad C_{f}=\phi_{f} \rho=\frac{\phi_{f} p_{f} M}{Z R T},
$$

where $p_{m}$ is the gas pressure in coal matrix, $C_{L}$ is the maximum adsorption concentration of the coal matrix, $p_{L}$ is the Langmuir pressure, $p_{f}$ is the gas pressure in fracture systems, and $\phi_{f}$ is the porosity of fracture systems.

2.2. Gas Flow Model. Considering the effects of fracture system deformation, fracture system permeability tensor $\mathbf{K}_{f}\left(x, p_{f}\right)$ can be written as

$$
\mathbf{K}_{f}\left(x, p_{f}\right)=\mathbf{K}_{0} e^{\beta\left(p_{f}-p_{0}\right)},
$$

where $p_{0}$ is the initial gas pressure in fracture systems, $\mathbf{K}_{0}$ is the fracture system permeability tensor under $p_{0}$, and $\beta$ is the permeability modulus with respect to gas pressure.

Coalbed gas flow in fracture systems is driven by pressure field and concentration field simultaneously. According to Darcy's law and Fick's diffusion law, the motion equation of gas flow in fracture systems can be written as

$$
\mathbf{u}=-\left(\frac{\mathbf{K}_{f}\left(x, p_{f}\right)}{\mu_{g}}+\frac{\mathbf{D}_{f} \phi_{f}}{p_{f}}\right) \nabla p_{f},
$$

where $\mathbf{u}$ is the total volume velocity of gas flow driven by multifield, $\mu_{g}$ is the gas viscosity, and $\mathbf{D}_{f}$ is the gas diffusion coefficient in fracture systems.

Then, according to the mass conservation law, the continuity equation of gas flow in fracture systems is

$$
\frac{\partial \rho \phi_{f}}{\partial t}+\nabla \cdot(\rho \mathbf{u})=\rho q_{m}
$$

where $q_{m}$ is the gas volume of interporosity flow from coal matrix to fracture systems. Using the state equation of real gas, the divergence term of (6) could be unfolded as the following form:

$$
\nabla \cdot(\rho \mathbf{u})=\rho \nabla \cdot \mathbf{u}+\mathbf{u} \cdot \nabla \rho=\rho \nabla \cdot \mathbf{u}+\frac{\rho}{p_{f}} \mathbf{u} \cdot \nabla p_{f} .
$$

Similarly, the capacity term could be unfolded as the following form:

$$
\begin{aligned}
\frac{\partial \rho \phi_{f}}{\partial t} & =\phi_{f} \frac{\partial \rho}{\partial t}+\rho \frac{\partial \phi_{f}}{\partial t} \\
& =\frac{\phi_{f} \rho}{p_{f}} \frac{\partial p_{f}}{\partial t}-c_{Z} \phi_{f} \rho \frac{\partial p_{f}}{\partial t}+c_{\phi} \phi_{f} \rho \frac{\partial p_{f}}{\partial t}
\end{aligned}
$$


where $c_{\phi}$ is the compressibility factor of $\phi_{f}$ and $c_{z}$ is the compressibility factor of $Z$, defined as

$$
c_{\phi}=\frac{1}{\phi_{f}} \frac{\partial \phi_{f}}{\partial p_{f}}, \quad c_{z}=\frac{1}{Z} \frac{\partial Z}{\partial p_{f}} .
$$

For the expression brevity, define

$$
\begin{gathered}
\mathbf{K}\left(x, p_{f}\right)=\frac{\mathbf{K}_{f}\left(x, p_{f}\right)}{\mu_{g}}+\frac{\mathbf{D}_{f} \phi_{f}}{p_{f}}, \\
c\left(x, p_{f}\right)=\frac{\phi_{f}}{p_{f}}-c_{z} \phi_{f}+c_{\phi} \phi_{f},
\end{gathered}
$$

and substitute motion equation (5) into (7); the continuity equation (6) can be rewritten as follows:

$$
c\left(x, p_{f}\right) \frac{\partial p_{f}}{\partial t}-\nabla \cdot\left(\mathbf{K}\left(x, p_{f}\right) \nabla p_{f}\right)-\frac{\mathbf{K}\left(x, p_{f}\right)^{-1}}{p_{f}} \mathbf{u}^{2}=q_{m} .
$$

Since the seepage velocity $\mathbf{u}$ is very low, the quadratic term $\mathbf{u}^{2}$ usually can be omitted in engineering application. Therefore, the more common form of continuity equation is as follows:

$$
c\left(x, p_{f}\right) \frac{\partial p_{f}}{\partial t}-\nabla \cdot\left(\mathbf{K}\left(x, p_{f}\right) \nabla p_{f}\right)=q_{m} .
$$

In addition, there are some other studies $[26,27]$ considering the influence of quadratic term $\mathbf{u}^{2}$. For example, Ranjbar et al. [26] have considered the gas density variation in space and solved the nonlinear equations using semianalytical methods. However, they did not consider the effect of gas desorption and deformable media. But their method may form a basis for application of semianalytical methods for problem like the one studied here and it will be useful to the readers.

According to Fick's first diffusion law, the pseudosteady state equation of gas diffusion in coal matrix can be written as

$$
\frac{d C_{a m}}{d t}=D_{m} \sigma\left(C_{E}\left(p_{f}\right)-C_{a m}\right),
$$

where $C_{a m}$ is the average gas concentration of a coal matrix block, $C_{E}\left(p_{f}\right)$ is the adsorbed concentration on the coal matrix surface and is defined as $C_{E}\left(p_{f}\right)=C_{L} p_{f} /\left(p_{L}+p_{f}\right)$, $D_{m}$ is the gas diffusion coefficient in coal matrix block, and $\sigma$ is the geometrical factor.

Combining (11) and (13), with corresponding initial and boundary conditions, we have the coalbed gas flow model as follows:

$$
\begin{aligned}
& \text { (i) } c\left(x, p_{f}\right) \frac{\partial p_{f}}{\partial t}-\nabla \cdot\left(\mathbf{K}\left(x, p_{f}\right) \nabla p_{f}\right)=q_{m}, \\
& x \in \Omega, \quad t \in[0, T], \\
& \text { (ii) } \frac{d C_{a m}}{d t}=D_{m} \sigma\left(C_{E}\left(p_{f}\right)-C_{a m}\right), \quad t \in[0, T] \text {, } \\
& \text { (iii) } p_{f}=p_{d}, \quad x \in \partial \Omega, t \in[0, T] \text {, }
\end{aligned}
$$

$$
\begin{aligned}
& \text { (iv) } p_{f}=p_{0}, \quad x \in \Omega, t=0, \\
& \text { (v) } C_{a m}=C_{0}, \quad x \in V_{m}, t=0,
\end{aligned}
$$

where $\Omega$ is the objective region for the two-dimensional problem with boundary $\partial \Omega,[0, T]$ is a time interval with $T \in(0, \infty]$, and $V_{m}$ is the region of a coal matrix block.

\section{Notations and Mixed Element Approximation Scheme}

In this section, we will present the mixed element approximation scheme for the coalbed gas flow model and give some notations.

3.1. Some Notations and Basic Approximation Results. For the convenience of subsequent analysis, we first give notations and basic approximation results. Define the inner product on $\Omega$ and its norm:

$$
(u, v)=\int_{\Omega} u(x) v(x) d x, \quad\|u\|_{L^{2}(\Omega)}=\left(\int_{\Omega} u^{2} d x\right)^{1 / 2} .
$$

Recall that the Sobolev space $H^{k}(\Omega)$ is the closure of $C^{\infty}(\Omega)$ in the norm

$$
\|u\|_{k}^{2}=\sum_{|\alpha| \leq k}\left\|D^{\alpha} u\right\|_{L^{2}(\Omega)}^{2} .
$$

Define the function spaces $W, V$ and their norms as follows:

$$
\begin{aligned}
W=L^{2}(\Omega), & \\
V & =H(\operatorname{div}, \Omega) \\
& =\left\{\mathbf{v}=\left(v_{1}, v_{2}\right) \in\left(L^{2}(\Omega)\right)^{2} \mid \nabla \cdot \mathbf{v} \in L^{2}(\Omega)\right\}, \\
\|\omega\|_{W} & =\left(\int_{\Omega} \omega^{2} d x\right)^{1 / 2}, \quad\|\mathbf{v}\|_{V}=\left\{\|\mathbf{v}\|^{2}+\|\nabla \cdot \mathbf{v}\|^{2}\right\}^{1 / 2} .
\end{aligned}
$$

Let $W_{h} \times V_{h} \subset W \times V$ be the mixed element function spaces such as $\mathrm{RT}_{k}$ with index $k$ and discretization parameter $h$. Now we define the RT projection $\Pi_{h}: V \rightarrow V_{h}$, satisfying

$$
\begin{gathered}
\left(\nabla \cdot\left(\mathbf{v}-\Pi_{h} \mathbf{v}\right), \omega_{h}\right)=0, \quad \mathbf{v} \in V, \omega_{h} \in W_{h}, \\
\left\|\mathbf{v}-\Pi_{h} \mathbf{v}\right\|_{0} \leq C\|\mathbf{v}\|_{s} h^{s}, \\
1 \leq s \leq k+1, \quad \forall \mathbf{v} \in V \cap\left(H^{s}(\Omega)\right)^{2}, \\
\left\|\nabla \cdot\left(\mathbf{v}-\Pi_{h} \mathbf{v}\right)\right\|_{0} \leq C\|\nabla \cdot \mathbf{v}\|_{s} h^{s}, \\
0 \leq s \leq k+1, \quad \forall \mathbf{v} \in V \cap H^{s}(\operatorname{div}, \Omega) .
\end{gathered}
$$

Define standard $L^{2}$ projection $P_{h}: W \rightarrow W_{h}$, satisfying

$$
\begin{gathered}
\left(P_{h} z-z, \omega_{h}\right)=0, \quad z \in W, \omega_{h} \in W_{h}, \\
\left\|z-P_{h} z\right\|_{0} \leq C\|z\|_{s} h^{s}, \quad 0 \leq s \leq k+1, \quad \forall z \in W \cap H^{s}(\Omega) .
\end{gathered}
$$


3.2. Mixed Element Approximation Scheme. We consider the case that the seepage-diffusion tensor $\mathbf{K}\left(x, p_{f}\right)$ is a diagonal matrix and $k_{i, i}>0(i=1,2)$ for the two-dimensional problem. That is to say, there exist positive constants $k_{m}$ and $k_{M}$ such that, for all $\xi \in R^{2}$,

$$
k_{m} \xi^{\prime} \xi \leq \xi^{\prime} \mathbf{K}\left(x, p_{f}\right) \xi \leq k_{M} \xi^{\prime} \xi .
$$

For the practical situation, there exist $c_{m}$ and $c_{M}$ such that the scalar coefficient $c\left(x, p_{f}\right)$ satisfies

$$
0<c_{m} \leq c\left(x, p_{f}\right) \leq c_{M}<\infty .
$$

Also, we can easily verify that the coefficients $k_{i, i}\left(p_{f}\right), c\left(p_{f}\right)$, and $q_{m}\left(p_{f}\right)$ satisfy the Lipschitz continuity. Since $\mathbf{K}\left(x, p_{f}\right)$ is a diagonal and invertible matrix, from (5) we have that

$$
\mathbf{K}\left(x, p_{f}\right)^{-1} \mathbf{u}+\nabla p_{f}=0 .
$$

Using the integration by parts and applying the boundary condition, we can define the mixed weak formation, which is to find $p_{f} \in W, \mathbf{u} \in V$ such that

$$
\begin{array}{ll}
\left(\mathbf{K}^{-1}\left(x, p_{f}\right) \mathbf{u}, \mathbf{v}\right)-\left(\nabla \cdot \mathbf{v}, p_{f}\right)=-\left(p_{d}, \mathbf{v} \cdot \mathbf{n}\right)_{\partial \Omega}, & \forall \mathbf{v} \in V, \\
\left(c\left(x, p_{f}\right) \frac{\partial p_{f}}{\partial t}, \omega\right)+(\nabla \cdot \mathbf{u}, \omega)=\left(q_{m}\left(p_{f}\right), \omega\right), & \forall \omega \in W,
\end{array}
$$

where $\mathbf{n}$ is the unit exterior normal vector to the $\partial \Omega$.

Replacing the original pressure $p_{f}$ and velocity $\mathbf{u}$ by their approximations, we get the semidiscrete mixed element approximate problem, which is to find $p_{h} \in W_{h}, \mathbf{u}_{h} \in V_{h}$ such that

$$
\begin{gathered}
\left(\mathbf{K}^{-1}\left(x, p_{h}\right) \mathbf{u}_{h}, \mathbf{v}_{h}\right)-\left(\nabla \cdot \mathbf{v}_{h}, p_{h}\right) \\
=-\left(p_{d}, \mathbf{v}_{h} \cdot \mathbf{n}\right)_{\partial \Omega}, \quad \forall \mathbf{v}_{h} \in V_{h}, \\
\left(c\left(x, p_{h}\right) \frac{\partial p_{h}}{\partial t}, \omega_{h}\right)+\left(\nabla \cdot \mathbf{u}_{h}, \omega_{h}\right) \\
=\left(q_{m}\left(t, p_{h}\right), \omega_{h}\right), \quad \forall \omega_{h} \in W_{h} .
\end{gathered}
$$

Let $\Delta t>0, M=T / \Delta t$, an integer, and $t_{n}=n \Delta t, n=0$, $1, \ldots, M$. We can define the full discrete mixed element approximate scheme with backward Euler time-discretization as follows:

$$
\begin{gathered}
\left(\mathbf{K}^{-1}\left(p_{h}^{n-1}\right) \mathbf{u}_{h}^{n}, \mathbf{v}_{h}\right)-\left(\nabla \cdot \mathbf{v}_{h}, p_{h}^{n}\right) \\
=-\left(p_{d}, \mathbf{v}_{h} \cdot \mathbf{n}\right)_{\partial \Omega}, \quad \forall \mathbf{v}_{h} \in V_{h}, \\
\left(c\left(p_{h}^{n-1}\right) \frac{p_{h}^{n}-p_{h}^{n-1}}{\Delta t}, \omega_{h}\right)+\left(\nabla \cdot \mathbf{u}_{h}^{n}, \omega_{h}\right) \\
=\left(q_{m}\left(p_{h}^{n-1}\right), \omega_{h}\right), \quad \forall \omega_{h} \in W_{h} .
\end{gathered}
$$

Since gas diffusion equation (13) is an ordinary differential equation, when $p_{h}^{n}$ is known, we can get $C_{a m}\left(t_{n}\right)$ as follows:

$$
C_{a m}\left(t_{n}\right)=C_{E}\left(p_{h}^{n}\right)-\left(C_{E}\left(p_{h}^{n}\right)-C_{0}\right) e^{-D_{m} \sigma t_{n}} .
$$

Then, the gas volume of interporosity flow from coal matrix to fracture systems could be calculated as follows:

$$
q_{m}\left(p_{h}^{n}\right)=-\left.\frac{1}{\rho} \frac{d C_{a m}}{d t}\right|_{t=t_{n}}=-\frac{1}{\rho} D_{m} \sigma\left(C_{E}\left(p_{h}^{n}\right)-C_{0}\right) e^{-D_{m} \sigma t_{n}}
$$

In practical calculation, alternative and iterative method is used to solve (25)-(27), and specific calculation procedure is listed as follows.

(i) For $n=1,2, \ldots, M$, when $p_{h}^{n-1}$ is known, $q_{m}\left(p_{h}^{n-1}\right)$ can be calculated using (27).

(ii) Then, substituting $q_{m}\left(p_{h}^{n-1}\right)$ into (25), $\left(p_{h}^{n}, \mathbf{u}_{h}^{n}\right)$ can be approximated using (25).

(iii) Lastly, when $p_{h}^{n}$ is known, $C_{a m}\left(t_{n}\right)$ can be calculated using (26).

Let $\tau_{h}$ be a quasiregular triangulation for the twodimensional rectangular region $\Omega$ with mesh size $h$. For a triangular element $T\left(A_{1} A_{2} A_{3}\right)$, let $\mathbf{x}_{i}=\left(x_{i}, y_{i}\right)$ be the coordinate of vertex $A_{i}$ and $\gamma_{i}$ the edge opposite to vertex $A_{i}$. Let $\mathbf{n}_{i}$ be the outward unit vector on the edge $\gamma_{i}$ and $h_{i}$ the length of the perpendicular dropped from the vertex $A_{i}$ onto the edge $\gamma_{i}, i=1,2,3$. We denote by $\digamma_{h}$ the set of all edges of the triangulation $\tau_{h}$.

The pressure function space $W_{h}$ is the space of piecewise constant functions:

$$
W_{h}=\left\{\omega_{h} \mid \omega_{h}=\omega_{k} \equiv \text { constant }_{k} \text { in } T_{k}, T_{k} \in \tau_{h}\right\}
$$

and the dimension of the space $W_{h}$ is equal to $m_{1}$-the total number of elements $T_{k}$ in the triangulation $\tau_{h}$. Each function $\omega_{h} \in W_{h}$ can be represented as a linear combination:

$$
\omega_{h}=\sum_{k=1}^{m_{1}} \omega_{k} \psi_{k}(\mathbf{x})
$$

where $\psi_{k}(\mathbf{x})$ is the basis function associated with the element $T_{k}$, satisfying

$$
\psi_{k}(\mathbf{x})=\left\{\begin{array}{ll}
1, & \mathbf{x} \in T_{k} \\
0, & \mathbf{x} \notin T_{k}
\end{array} \quad k=1 \cdots m_{1} .\right.
$$

The velocity function space $V_{h}$ is chosen to be the $\operatorname{RT}_{0}\left(\Omega, \tau_{h}\right)$, defined as

$$
V_{h}=\mathrm{RT}_{0}\left(\Omega, \tau_{h}\right)=\left\{\mathbf{v}_{h} \mid \mathbf{v}_{h}=\left(\begin{array}{c}
a_{x}+b x \\
a_{y}+b y
\end{array}\right) \text { in } T_{k}, T_{k} \in \tau_{h}\right\}
$$

and the dimension of the space $V_{h}$ is equal to $m_{2}$-the total number of edges $\gamma_{j} \in F_{h}$. Each function $\mathbf{v}_{h} \in W_{h}$ can be represented as a linear combination

$$
\mathbf{v}_{h}=\sum_{j=1}^{m_{2}} v_{j} \phi_{j}(\mathbf{x})
$$


where $v_{j}=\mathbf{v}_{h} \cdot \mathbf{n}_{j}$ and $\phi_{j}$ is the basis function associated with the edge $\gamma_{j} \in F$, satisfying

$$
\phi_{j} \cdot \mathbf{n}_{j^{\prime}}= \begin{cases}1, & j=j^{\prime} \\ 0, & j \neq j^{\prime}\end{cases}
$$

To be specific, for a triangle element $T_{k}$, the basis functions $\phi_{i}(i=1,2,3)$ are determined by the following formulas:

$$
\phi_{i}(\mathbf{x})=\frac{1}{h_{i}}\left(\mathbf{x}-\mathbf{x}_{i}\right) \equiv \frac{\left|\gamma_{i}\right|}{2|T|}\left(\mathbf{x}-\mathbf{x}_{i}\right),
$$

where $\mathbf{x}_{i}=\left(x_{i}, y_{i}\right)$ are the coordinates of the vertices $A_{i}(i=$ $1,2,3)$ and $|T|$ is the area of triangle element $T_{k}$.

Now we use the basis functions $\psi_{k}(\mathbf{x})\left(k=1 \cdots m_{1}\right)$ and $\phi_{j}(\mathbf{x})\left(j=1 \cdots m_{2}\right)$ to represent $p_{h}^{n}$ and $\mathbf{u}_{h}^{n}$ :

$$
p_{h}^{n}=\sum_{k=1}^{m_{1}} p_{k}^{n} \psi_{k}(\mathbf{x}), \quad \mathbf{u}_{h}^{n}=\sum_{j=1}^{m_{2}} u_{j}^{n} \phi_{j}(\mathbf{x}) .
$$

Substituting (35) into (25) and setting $\omega_{h}=\psi_{k}\left(k=1 \cdots m_{1}\right)$ and $\mathbf{v}_{h}=\phi_{j}(\mathbf{x})\left(j=1 \cdots m_{2}\right)$, full discrete mixed element approximation scheme (25) can be written as follows:

$$
\begin{gathered}
\sum_{j=1}^{m_{2}}\left(\mathbf{K}^{-1}\left(p_{h}^{n-1}\right) \phi_{j}, \phi_{t}\right) u_{j}^{n}-\sum_{k=1}^{m_{1}}\left(\nabla \cdot \phi_{t}, \psi_{k}\right) p_{k}^{n} \\
=-\left(p_{d}, \phi_{t} \cdot \mathbf{n}\right)_{\partial \Omega}, \quad t=1,2 \cdots m_{2}, \\
\Delta t \sum_{j=1}^{m_{2}}\left(\nabla \cdot \phi_{j}, \psi_{l}\right) u_{j}^{n}+\sum_{k=1}^{m_{1}}\left(c\left(p_{h}^{n-1}\right) \psi_{k}, \psi_{l}\right) p_{k}^{n} \\
=\Delta t\left(q_{m}\left(p_{h}^{n-1}\right), \psi_{l}\right)+\left(c\left(p_{h}^{n-1}\right) p_{h}^{n-1}, \psi_{l}\right) \\
l=1,2 \cdots m_{1} .
\end{gathered}
$$

We introduce matrices and vectors as follows:

$$
\begin{gathered}
\mathbf{A}=\left(A_{i j}\right)_{m_{2} \times m_{2}}, \quad \mathbf{B}=\left(B_{i j}\right)_{m_{2} \times m_{1}}, \quad \mathbf{C}=\left(C_{i j}\right)_{m_{1} \times m_{1}}, \\
\mathbf{U}^{n}=\left(u_{j}^{n}\right)_{m_{2} \times 1}, \quad \mathbf{P}^{n}=\left(p_{k}^{n}\right)_{m_{1} \times 1}, \\
\mathbf{b}_{1}=\left(b_{1, i}\right)_{m_{2} \times 1}, \quad \mathbf{b}_{2}=\left(b_{2, i}\right)_{m_{1} \times 1},
\end{gathered}
$$

where

$$
\begin{gathered}
A_{i j}=\int_{\Omega} \mathbf{K}^{-1}\left(p_{h}^{n-1}\right) \phi_{j} \phi_{j} d x, \quad B_{i j}=\int_{\Omega} \nabla \cdot \phi_{i} \psi_{j} d x \\
C_{i j}=\int_{\Omega} c\left(p_{h}^{n-1}\right) \psi_{i} \psi_{j} d x \\
b_{1, i}=-\int_{\partial \Omega} p_{d}\left(\phi_{i} \cdot \mathbf{n}\right) d x \\
b_{2, i}=\Delta t \int_{\Omega} q_{m}\left(p_{h}^{n-1}\right) \psi_{i} d x+\int_{\Omega} c\left(p_{h}^{n-1}\right) p_{h}^{n-1} \psi_{i} d x .
\end{gathered}
$$

TABLE 1: Relative errors and convergence rates for $p_{h}$.

\begin{tabular}{lcc}
\hline Resolution & Error $\left(\frac{\left\|p_{h}^{N}-p_{1 / 128}^{N}\right\|_{L^{2}}}{\left\|p_{1 / 128}^{N}\right\|_{L^{2}}}\right)$ & Rate \\
\hline$h=\frac{1}{4}$ & $6.67 E-2$ & - \\
$h=\frac{1}{8}$ & $3.60 E-2$ & -0.8903 \\
$h=\frac{1}{16}$ & $1.91 E-2$ & -0.9131 \\
$h=\frac{1}{32}$ & $9.63 E-3$ & -0.9880 \\
$h=\frac{1}{64}$ & $4.81 E-3$ & -1.0015 \\
\hline
\end{tabular}

Therefore, (36) can be written in a matrix form as follows:

$$
\left(\begin{array}{cc}
\mathbf{A} & -\mathbf{B} \\
\Delta t \mathbf{B}^{T} & \mathbf{C}
\end{array}\right)\left(\begin{array}{l}
\mathbf{U}^{n} \\
\mathbf{P}^{n}
\end{array}\right)=\left(\begin{array}{l}
\mathbf{b}_{1} \\
\mathbf{b}_{2}
\end{array}\right)
$$

where $\mathbf{B}^{T}$ is the transpose of $\mathbf{B}$. Solving linear algebra problem (39), we can get approximation solutions $\mathbf{P}^{n}$ and $\mathbf{U}^{n}$ at $n$th time step, simultaneously.

\section{Numerical Examples}

In this section, we carry out numerical experiments using the lowest order Raviart-Thomas mixed finite elements $\mathrm{RT}_{0}$ for the gas flow problem in deformable CBM reservoirs.

Example 1. In order to verify the convergence, the test region is selected as unit square; that is, $\Omega=[0,1] \times[0,1]$, and 6 levels for $h=1 / 4,1 / 8,1 / 16,1 / 32,1 / 64,1 / 128$ are computed to estimate the convergence rate. Since we cannot get the analytical solution $p_{f}$, u, and $C_{a m}$ for the problem (14), we use $\left\|p_{h}^{N}-p_{1 / 128}^{N}\right\|_{L^{2}} /\left\|p_{1 / 128}^{N}\right\|_{L^{2}},\left\|\mathbf{u}_{h}^{N}-\mathbf{u}_{1 / 128}^{N}\right\|_{L^{2}} /\left\|\mathbf{u}_{1 / 128}^{N}\right\|_{L^{2}}$, and $\left\|C_{a m, h}^{N}-C_{a m, 1 / 128}^{N}\right\|_{L^{2}} /\left\|C_{a m, 1 / 128}^{N}\right\|_{L^{2}}$ as the criterion of convergence for the pressure, velocity, and concentration. Error estimates in $L^{2}$-norm and convergence rate estimates for $p_{h}, \mathbf{u}_{h}$, and $C_{a m, h}$ are listed in Tables 1, 2, and 3, respectively. We can find that the approximation solutions $p_{h}$, $\mathbf{u}_{h}$, and $C_{a m, h}$ could achieve first-order convergence rate (see Figure 1).

Example 2. For a simple application, the scale of objective region $\Omega$ is $100 \mathrm{~m} \times 100 \mathrm{~m}$ and the mesh size $h=2.5 \mathrm{~m}$. There is a production well at the center of region $\Omega$ with the production rate $q_{g}$. Simulation parameters are listed in Table 4.

Substituting the parameter value into calculation procedure, we can get the numerical solutions, so as to describe the dynamic characteristic of gas flow in deformable CBM reservoirs.

Since average pressure could reflect the decrement of reservoir driving energy during production process, Figures 2 and 3 illustrate the gas average pressure in fracture systems varying with time $t$ and show the effects of $D_{m}$ and $\beta$ on average pressure, respectively. In Figure 2, the model 
TABLE 2: Relative errors and convergence rates for $\mathbf{u}_{h}$.

\begin{tabular}{lcc}
\hline Resolution & Error $\left(\frac{\left\|\mathbf{u}_{h}^{N}-\mathbf{u}_{1 / 128}^{N}\right\|_{L^{2}}}{\left\|\mathbf{u}_{1 / 128}^{N}\right\|_{L^{2}}}\right)$ & Rate \\
\hline$h=\frac{1}{4}$ & $1.17 E-2$ & - \\
$h=\frac{1}{8}$ & $6.23 E-3$ & -0.9092 \\
$h=\frac{1}{16}$ & $3.24 E-3$ & -0.9823 \\
$h=\frac{1}{32}$ & $1.64 E-3$ & -1.0053 \\
$h=\frac{1}{64}$ & $8.17 E-4$ & \\
\hline
\end{tabular}

TABLE 3: Relative errors and convergence rates for $C_{a m, h}$.

\begin{tabular}{lcc}
\hline Resolution & Error $\left(\frac{\left\|C_{a m, h}^{N}-C_{a m, 1 / 128}^{N}\right\|_{L^{2}}}{\left\|C_{a m, 1 / 128}^{N}\right\|_{L^{2}}}\right)$ & Rate \\
\hline$h=\frac{1}{4}$ & $4.77 E-2$ & - \\
$h=\frac{1}{8}$ & $2.54 E-2$ & -0.9092 \\
$h=\frac{1}{16}$ & $1.31 E-2$ & -0.9553 \\
$h=\frac{1}{32}$ & $6.59 E-3$ & -0.9912 \\
$h=\frac{1}{64}$ & $3.29 E-3$ & -1.0022 \\
\hline
\end{tabular}

has the initial reservoir pressure of $10 \mathrm{MPa}$, and diffusion coefficient of coal matrix $D_{m}$ is taken as $1 \times 10^{-7}, 5 \times 10^{-8}$, $1 \times 10^{-8}$, and $5 \times 10^{-9} \mathrm{~m}^{3} / \mathrm{s}$, respectively, so as to analyze the effects of $D_{m}$ on average pressure in fracture systems. In Figure 2, we have found that pressure variation curves could be divided into 3 stages. Firstly, at the initial stage, since coalbed gas could not desorb and diffuse from matrix into fracture systems instantly, average pressure in fracture systems declines rapidly. At this stage, we have found when $D_{m}$ is increasing, the initial stage became shorter. It is because that larger $D_{m}$ could make fracture systems get pressure compensation from coal matrix more quickly. Secondly, at the stable stage, with gas desorption increasing from the coal matrix into fracture systems, fracture systems could get more pressure compensation; thus, the average pressure drop speed slows down. We have also found, with a bigger $D_{m}$, fracture systems could maintain a higher average pressure, while the stable stage would be shorter. Lastly, at the last stage, due to the decline of gas concentration in matrix gas desorption rate decreases, resulting in the pressure drop speed becoming rapid once again. Meanwhile, when $D_{m}$ is larger, the last stage appears at an earlier time. The double porosity characteristics of CBM reservoirs have been just shown through the pressure variation process presented above.

In Figure 3, the permeability modulus $\beta$ is set as $1 \times$ $10^{-1}, 1 \times 10^{-3}$, and $1 \times 10^{-5}$, respectively, so as to analyze the effects of $\beta$ on average pressure. We have found that pressure drop curves with different $\beta$ are almost coincident

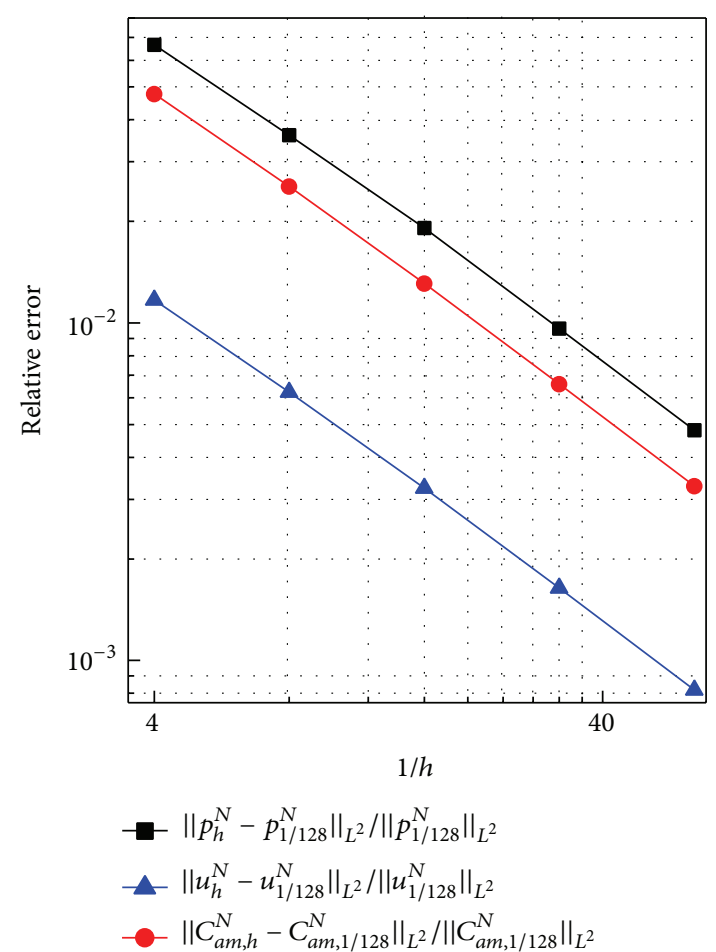

Figure 1: Convergence rates for $\left\|p_{h}^{N}-p_{1 / 128}^{N}\right\|_{L^{2}} /\left\|p_{1 / 128}^{N}\right\|_{L^{2}}$, $\left\|\mathbf{u}_{h}^{N}-\mathbf{u}_{1 / 128}^{N}\right\|_{L^{2}} /\left\|\mathbf{u}_{1 / 128}^{N}\right\|_{L^{2}}$, and $\left\|C_{a m, h}^{N}-C_{a m, 1 / 128}^{N}\right\|_{L^{2}} /\left\|C_{a m, 1 / 128}^{N}\right\|_{L^{2}}$.

TABle 4: Parameters for simulation.

\begin{tabular}{lc}
\hline Coefficient & Value \\
\hline$\Omega$ & $100 \mathrm{~m} \times 100 \mathrm{~m}$ \\
$\phi_{f}$ & 0.15 \\
$p_{0}$ & $10 \mathrm{MPa}$ \\
$C_{0}$ & $22.5 \mathrm{~kg} / \mathrm{m}^{3}$ \\
$D_{m}$ & $10^{-8} \mathrm{~m}^{3} / \mathrm{s}$ \\
$P_{L}$ & $6 \mathrm{MPa}$ \\
$c_{Z}$ & $10^{-3}$ \\
$q_{g}$ & $180 \mathrm{~m}^{3} / \mathrm{h}$ \\
$h$ & $2.5 \mathrm{~m}$ \\
$k_{0}$ & $0.01 \mathrm{md}$ \\
$\mu_{g}$ & $0.65 \mathrm{mPa} \cdot \mathrm{s}$ \\
$D_{f}$ & $10^{-6} \mathrm{~m}^{3} / \mathrm{s}$ \\
$C_{L}$ & $36 \mathrm{~kg} / \mathrm{m}^{3}$ \\
$c_{\phi}$ & $5 \times 10^{-2}$ \\
$\beta$ & $1.25 \times 10^{-3}$ \\
\hline
\end{tabular}

at early time, which indicates that fracture deformation has no evident effects on permeability and pressure at this stage. Essentially, with the fracture pressure dropping, the effects of fracture deformation on permeability become significant, and, conversely, the permeability could also affect fracture pressure. That is to say, the effects of permeability and pore pressure are mutual. Subsequently, we have found pressure drop curves become apart in Figure 3. Also, we have found that the larger the $\beta$ is, the lower the average pressure will be. From the definition of $\beta$, we know that $\beta$ reflects 


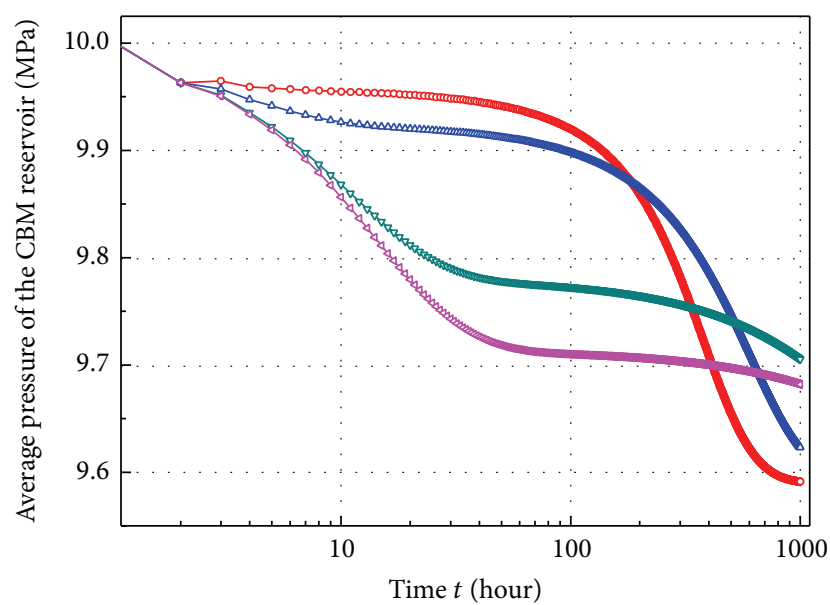

$$
\begin{array}{ll}
\multimap D_{m}=1 \times 10^{-7} & \rightarrow D_{m}=1 \times 10^{-8} \\
\multimap D_{m}=5 \times 10^{-8} & \multimap D_{m}=5 \times 10^{-9}
\end{array}
$$

FIGURE 2: Gas average pressure of fracture systems with different $D_{m}$.

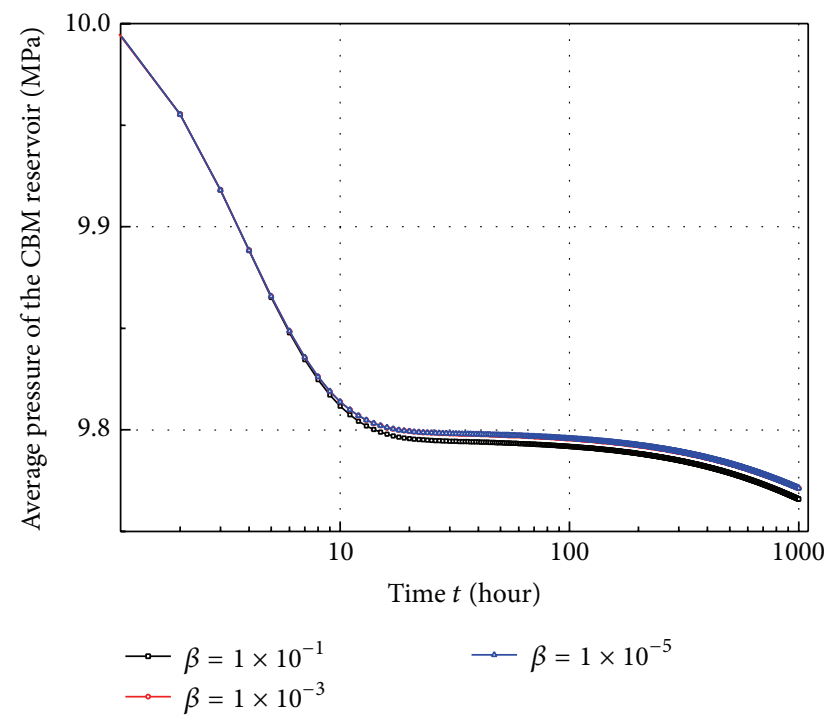

Figure 3: Gas average pressure of fracture systems with different $\beta$.

the effects of fracture system deformation on the permeability $\mathbf{K}_{f}$. Thus, when $\beta$ is larger, $\mathbf{K}_{f}$ decreases more significantly with $p_{f}$ dropping, such that CBM reservoirs can only get less pressure compensation from outer boundary, resulting in a lower average pressure.

Figure 4 shows the bottom hole pressure varying with time $t$, and the diffusion coefficient $D_{m}$ of coal matrix is taken as $1 \times 10^{-7}, 5 \times 10^{-8}, 1 \times 10^{-8}$, and $5 \times 10^{-9} \mathrm{~m}^{3} / \mathrm{s}$, respectively, so as to analyze the effects of $D_{m}$ on bottom hole pressure. Since the bottom hole pressure is the direct reflection of production effects, the bottom hole pressure drops sharply from 10 MPa to about $4.25 \mathrm{MPa}$ after starting production, and then there is a pressure recovery due to the gas desorption from coal matrix to fracture systems. Thus, this causes an early fluctuation before reaching a stable state.

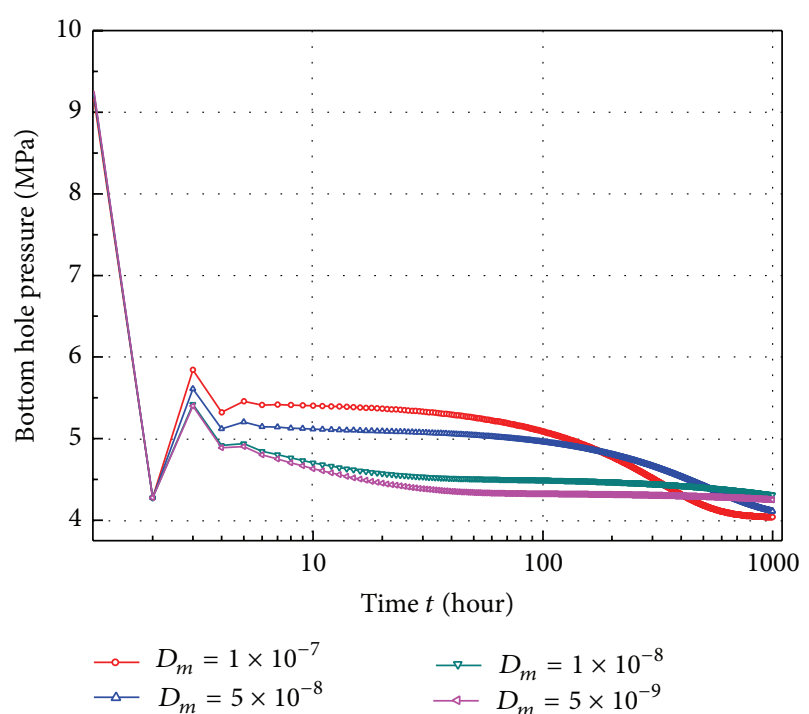

FIGURE 4: Bottom hole pressure of CBM reservoirs with different $D_{m}$.

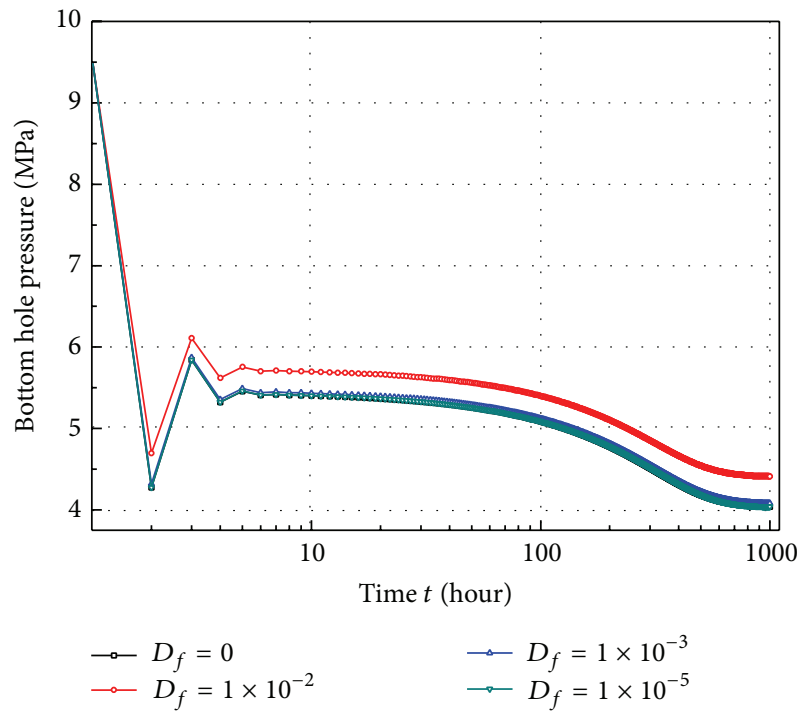

FIGURE 5: Bottom hole pressure of CBM reservoirs with different $D_{f}$.

In the subsequent stable stage, we have found that a bigger diffusion coefficient $D_{m}$ could make more coalbed gas desorb into fracture systems and result in a higher bottom hole pressure. Then, at the last stage, due to the gas desorption decreasing, the effects of $D_{m}$ become weak and bottom hole pressure curves tend to be close. Put simply, the effects of $D_{m}$ are evident at stable stage, while they are not so evident at the early and last stage.

Coalbed gas flow in fracture systems is driven by pressure field and concentration field simultaneously; thus, the effects of gas diffusion in fracture systems need to be investigated. In Figure 5, we set fracture diffusion coefficient $D_{f}$ as $0,1 \times 10^{-2}$, $1 \times 10^{-3}$, and $1 \times 10^{-5} \mathrm{~m}^{3} / \mathrm{s}$, respectively, so as to analyze 
the effects of gas diffusion in fracture systems. We have found that when $D_{f}$ is larger, the bottom hole pressure is higher. Specifically, the pressure difference between $D_{f}=$ $1 \times 10^{-2}$ and $D_{f}=0$ is about $0.35 \mathrm{MPa}$ all through the stable stage in Figure 5. That is to say, existence of gas diffusion in fracture systems could make fracture systems get more pressure compensation from outer boundary, resulting in a higher bottom hole pressure. Thus, it is very meaningful to consider gas diffusion in fracture system.

In order to illustrate the gas desorption dynamic process from coal matrix into fracture systems, we show the gas average desorption rate varying with time $t$ in Figures 6 and 7 . In Figure 6, the diffusion coefficient $D_{m}$ is taken as $1 \times 10^{-7}$, $5 \times 10^{-8}, 1 \times 10^{-8}$, and $5 \times 10^{-9} \mathrm{~m}^{3} / \mathrm{s}$, respectively, so as to investigate the effects of matrix diffusion coefficient on gas desorption process. According to equilibrium desorption model, we know that gas desorption rate is affected by gas average concentration $C_{a m}$ in matrix, fracture pressure $p_{f}$, and diffusion coefficient $D_{m}$. During production process, as fracture pressure $p_{f}$ and gas average concentration $C_{a m}$ decline, there are two stages in gas desorption process. At first half stage, due to quick drawdown of fracture pressure, gas concentration $C_{E}\left(p_{f}\right)$ on matrix surface declines sharply, and then the gas average desorption rate increased to the maximum. Then, at the second half stage, the desorption rate declines due to the reduction of gas average concentration $C_{a m}$. In Figure 6, we have also found when $D_{m}$ is larger, average desorption rate will be higher and peak desorption rate appears at an earlier moment. In Figure 7, the fracture diffusion coefficient $D_{f}$ is taken as $0,1 \times 10^{-2}, 1 \times 10^{-3}$, and $1 \times 10^{-5} \mathrm{~m}^{3} / \mathrm{s}$, respectively. Since the effects of $D_{f}$ on desorption rate are indirect and reflected by means of fracture pressure $p_{f}$, the effects of $D_{f}$ are not evident at the starting and ending time. However, we have still found that the larger the $D_{f}$ is, the higher the peak desorption rate will be.

In order to reflect the remaining reserves of coalbed gas in coal matrix, we show the gas average concentration in coal matrix varying with time $t$ in Figures 8 and 9. In Figure $8, D_{m}$ is taken as $1 \times 10^{-7}, 5 \times 10^{-8}, 1 \times 10^{-8}$, and $5 \times 10^{-9} \mathrm{~m}^{3} / \mathrm{s}$, respectively. We have found that the gas average concentration declines slowly at the early stage on account of the existence of desorption delay phenomenon. Then, due to gas desorption increasing from coal matrix into fracture systems, the average concentration in coal matrix declines quickly at the later stage. At last stage, due to gas desorption rate decreasing, the concentration drop speed becomes slow once again. Also, in Figure 8, we have found concentration curves are almost coincident at early time. At subsequent stages, when $D_{m}$ is larger, the average concentration is lower and the concentration drop speed is quicker. It is because that larger $D_{m}$ could accelerate gas desorption rate. In Figure 9, we have found that the effects of initial permeability $k_{0}$ are not evident at the early stage, due to the existence of desorption delay phenomenon. And then, at the later half stage, the average concentration increases with $k_{0}$ increasing. It indicates that the CBM reservoir with higher permeability could get more pressure compensation from outer boundary, resulting in higher pore pressure and matrix concentration.

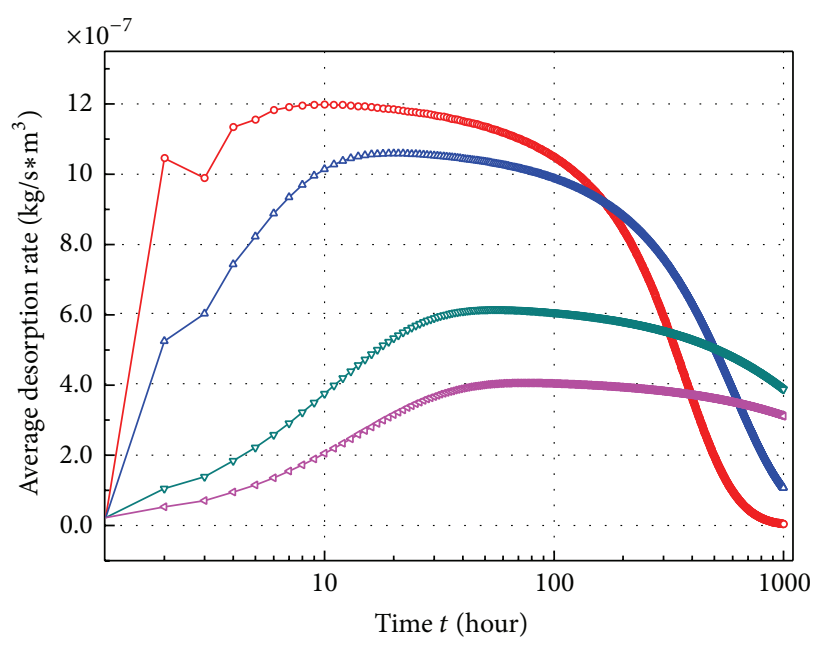

$$
\begin{array}{ll}
\multimap D_{m}=1 \times 10^{-7} & \rightarrow D_{m}=1 \times 10^{-8} \\
\rightarrow D_{m}=5 \times 10^{-8} & \multimap D_{m}=5 \times 10^{-9}
\end{array}
$$

Figure 6: Gas average desorption rate with different $D_{m}$.

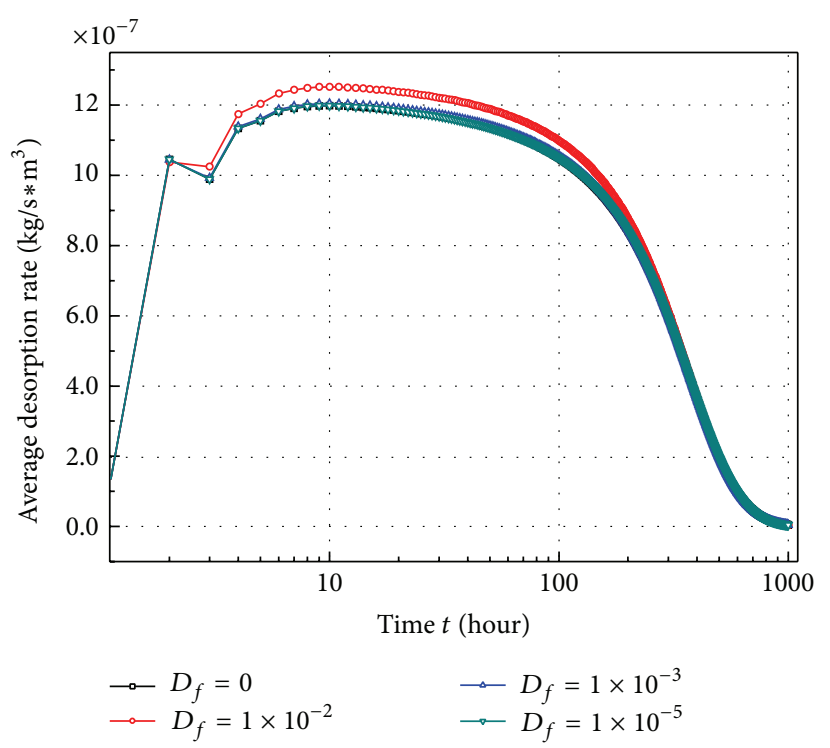

FIGURE 7: Gas average desorption rate with different $D_{f}$.

\section{Conclusions}

(1) In this paper, we present a desorption-diffusionseepage model of gas flow in deformable CBM reservoirs, in which the effects of fracture system deformation have been considered.

(2) We introduce a mixed finite element method to approximate the coalbed gas pressure and velocity, simultaneously, and establish error estimates for the numerical solutions.

(3) We carry out numerical experiments using the lowest order Raviart-Thomas mixed finite elements $\mathrm{RT}_{0}$. Numerical results in Example 1 indicate that the approximation solutions $p_{h}, \mathbf{u}_{h}$, and $C_{a m, h}$ 


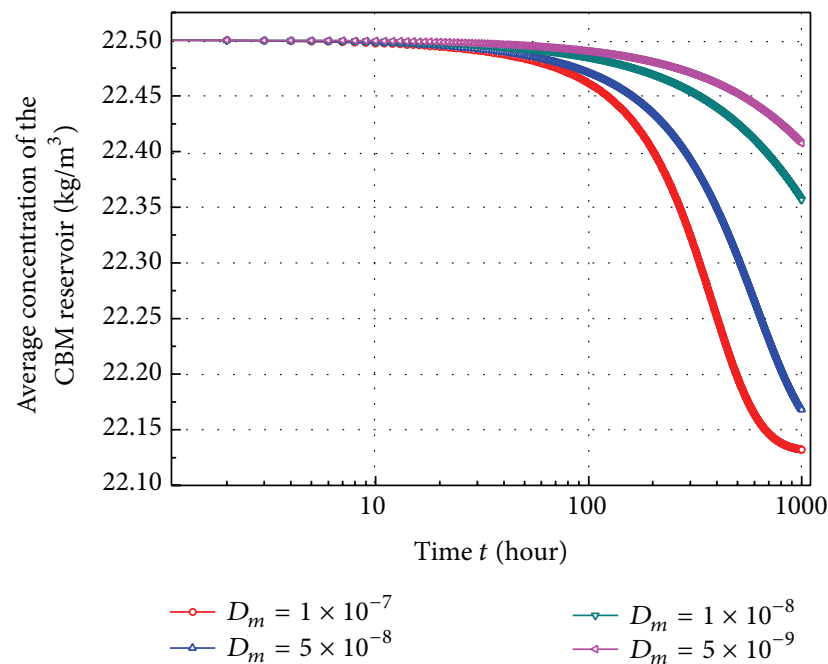

FIGURE 8: Gas average concentration in coal matrix with different $D_{m}$.

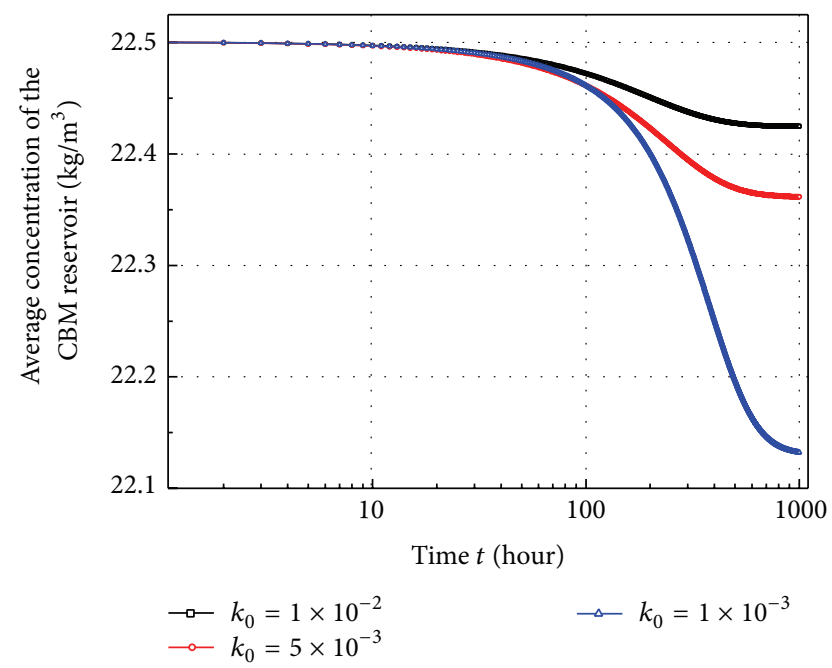

FIGURE 9: Gas average concentration in coal matrix with different $k_{0}$.

could achieve first-order convergence rate. Numerical results in Example 2 have shown that the existence of fracture system deformation phenomenon will result in a lower gas average pressure.

\section{Conflict of Interests}

The author declares that there is no conflict of interests regarding the publication of this paper.

\section{Acknowledgment}

The work described in this paper was a part of research work of project supported by National Natural Science Foundation of China (Grant nos. 91330106 and 11171190).

\section{References}

[1] M. Lu and L. D. Connell, "A dual-porosity model for gas reservoir flow incorporating adsorption behaviour. I. Theoretical development and asymptotic analyses," Transport in Porous Media, vol. 68, no. 2, pp. 153-173, 2007.

[2] F. Gu and R. Chalaturnyk, "Permeability and porosity models considering anisotropy and discontinuity of coalbeds and application in coupled simulation," Journal of Petroleum Science and Engineering, vol. 74, no. 3-4, pp. 113-131, 2010.

[3] H.-H. Liu and J. Rutqvist, "A new coal-permeability model: internal swelling stress and fracture-matrix interaction," Transport in Porous Media, vol. 82, no. 1, pp. 157-171, 2010.

[4] Z. Pan and L. D. Connell, "A theoretical model for gas adsorption-induced coal swelling," International Journal of Coal Geology, vol. 69, no. 4, pp. 243-252, 2007.

[5] P. Thararoop, Z. T. Karpyn, and T. Ertekin, "Development of a coal shrinkage swelling model accounting for water content in the micropores," International Journal of Mining and Mineral Engineering, vol. 1, pp. 346-364, 2009.

[6] P. Thararoop, Z. T. Karpyn, and T. Ertekin, "Development of a multi-mechanistic, dual-porosity, dual-permeability, numerical flow model for coalbed methane reservoirs," Journal of Natural Gas Science and Engineering, vol. 8, pp. 121-131, 2012.

[7] M. Pillalamarry, S. Harpalani, and S. Liu, "Gas diffusion behavior of coal and its impact on production from coalbed methane reservoirs," International Journal of Coal Geology, vol. 86, no. 4, pp. 342-348, 2011.

[8] C. R. Clarkson and R. M. Bustin, "Coalbed methane: current field-based evaluation methods," SPE Reservoir Evaluation and Engineering, vol. 14, no. 1, pp. 60-75, 2011.

[9] E. Ranjbar and H. Hassanzadeh, "Matrix-fracture transfer shape factor for modeling flow of a compressible fluid in dual-porosity media," Advances in Water Resources, vol. 34, no. 5, pp. 627-639, 2011.

[10] K. Aminian and S. Ameri, "Predicting production performance of CBM reservoirs," Journal of Natural Gas Science and Engineering, vol. 1, no. 1-2, pp. 25-30, 2009.

[11] G. B. C. Young, "Computer modeling and simulation of coalbed methane resources," International Journal of Coal Geology, vol. 35, no. 1-4, pp. 369-379, 1998.

[12] E. Unsal, S. K. Matthäi, and M. J. Blunt, "Simulation of multiphase flow in fractured reservoirs using a fracture-only model with transfer functions," Computational Geosciences, vol. 14, no. 4, pp. 527-538, 2010.

[13] L. R. Herrmann, "Finite element bending analysis for plates," Journal of Engineering Mechanics, vol. 93, pp. 13-26, 1967.

[14] R. Raviart and J. M. Thomas, "A mixed f inite element method for second order elliptic problems," in Lecture Notes in Mathematics, vol. 606, pp. 292-315, 1977.

[15] J. Nedelec, "Mixed finite elements in $\mathbb{R}^{3}$," Numerische Mathematik, vol. 35, no. 3, pp. 315-341, 1980.

[16] F. Brezzi, J. Douglas, and L. D. Marini, "Two families of mixed finite elements for second order elliptic problems," Numerische Mathematik, vol. 47, no. 2, pp. 217-235, 1985.

[17] F. Brezzi, J. Douglas, R. Durán, and M. Fortin, "Mixed finite elements for second order elliptic problems in three variables," Numerische Mathematik, vol. 51, no. 2, pp. 237-250, 1987.

[18] Z. Chen and J. Douglas Jr., "Prismatic mixed finite elements for second order elliptic problems," Calcolo, vol. 26, pp. 135-148, 1989. 
[19] J. Douglas, F. Furtado, and F. Pereira, "On the numerical simulation of waterflooding of heterogeneous petroleum reservoirs," Computational Geosciences, vol. 1, no. 2, pp. 155-190, 1997.

[20] J. Douglas Jr., F. Pereira, and L.-M. Yeh, "A locally conservative Eulerian-Lagrangian numerical method and its application to nonlinear transport in porous media," Computational Geosciences, vol. 4, no. 1, pp. 1-40, 2000.

[21] J. Douglas Jr., D. Frías, N. Henderson, and F. Pereira, "Simulation of single-phase multicomponent flow problems in gas reservoirs by Eulerian-Lagrangian techniques," Transport in Porous Media, vol. 50, no. 3, pp. 307-342, 2003.

[22] H. Wang, "An optimal-order error esti mate for a family of ELLAM-MFEM approximations to porous medium flow," SIAM Journal on Numerical Analysis, vol. 46, no. 4, pp. 21332152, 2008.

[23] H. Wang, W. Zhao, and M. S. a. Espedal, "A componentbased Eulerian-Lagrangian formulation for multicomponent multiphase compositional flow and transport in porous media," SIAM Journal on Scientific Computing, vol. 35, no. 2, pp. B462B486, 2013.

[24] B. Li and W. Sun, "Unconditional convergence and optimal error estimates of a Galerkin-mixed FEM for incompressible miscible flow in porous media," SIAM Journal on Numerical Analysis, vol. 51, no. 4, pp. 1959-1977, 2013.

[25] J. G. Wang, A. Kabir, J. Liu, and Z. Chen, "Effects of non-Darcy flow on the performance of coal seam gas wells," International Journal of Coal Geology, vol. 93, pp. 62-74, 2012.

[26] E. Ranjbar, H. Hassanzadeh, and Z. Chen, "Semianalytical solutions for release of fluids from rock matrix blocks with different shapes, sizes, and depletion regimes," Water Resources Research, vol. 49, no. 4, pp. 2174-2196, 2013.

[27] J. Yao, D. Fan, C. Wang, and K. Zhang, "Dynamic pressure analysis of horizontal wells in low permeability reservoirs with the effect of quadratic gradient term," Acta Petrolei Sinica, vol. 32, no. 3, pp. 479-483, 2011. 


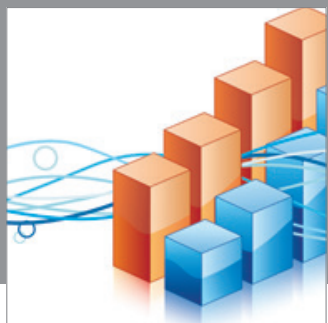

Advances in

Operations Research

mansans

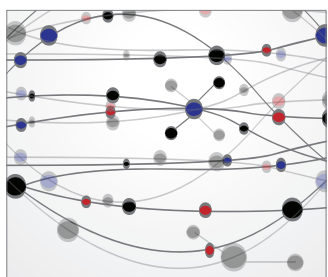

The Scientific World Journal
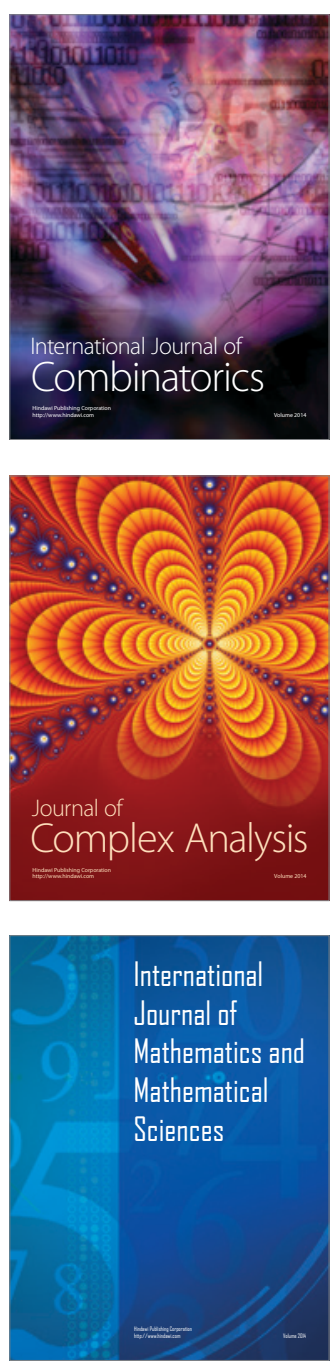
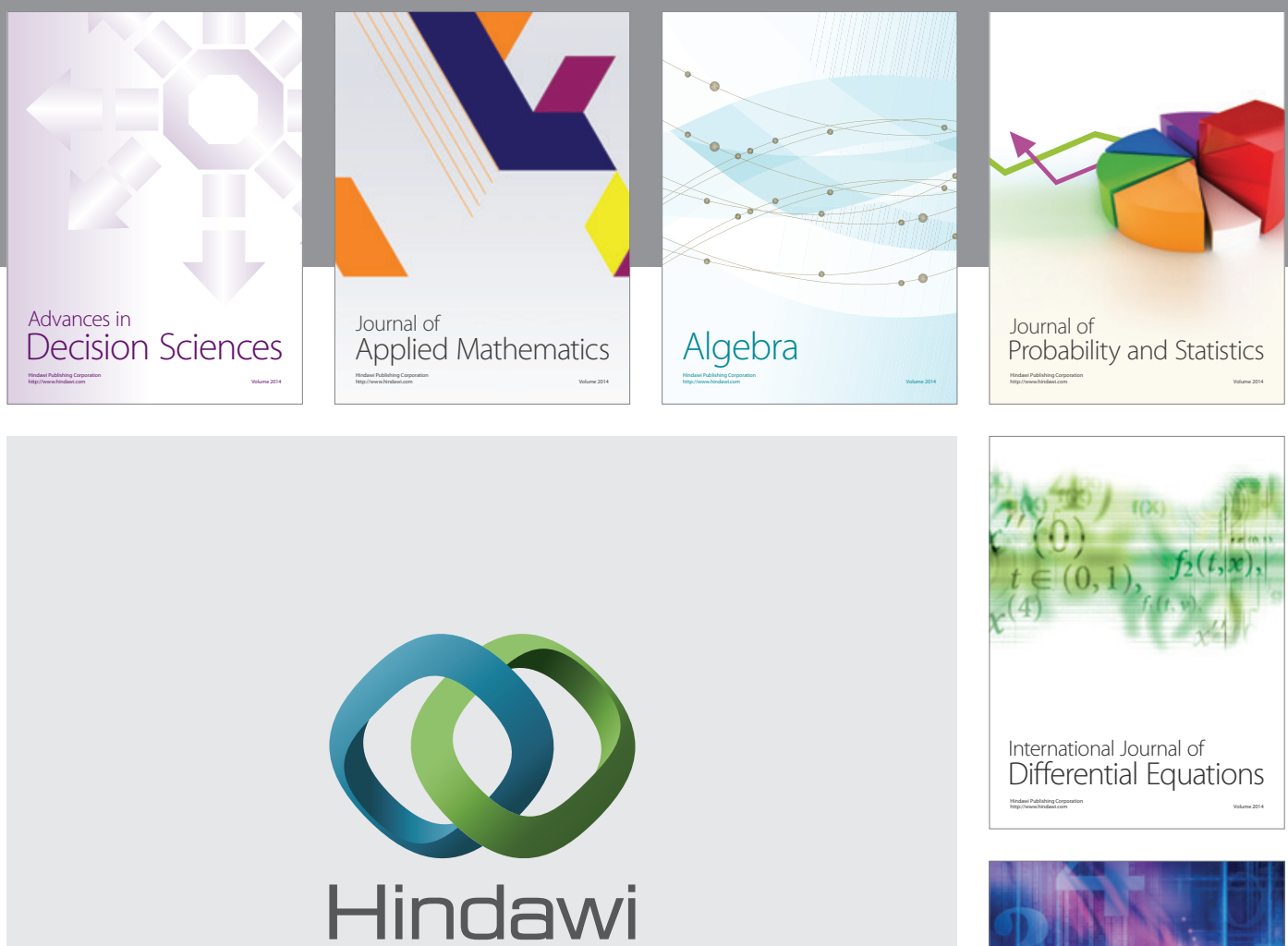

Submit your manuscripts at http://www.hindawi.com
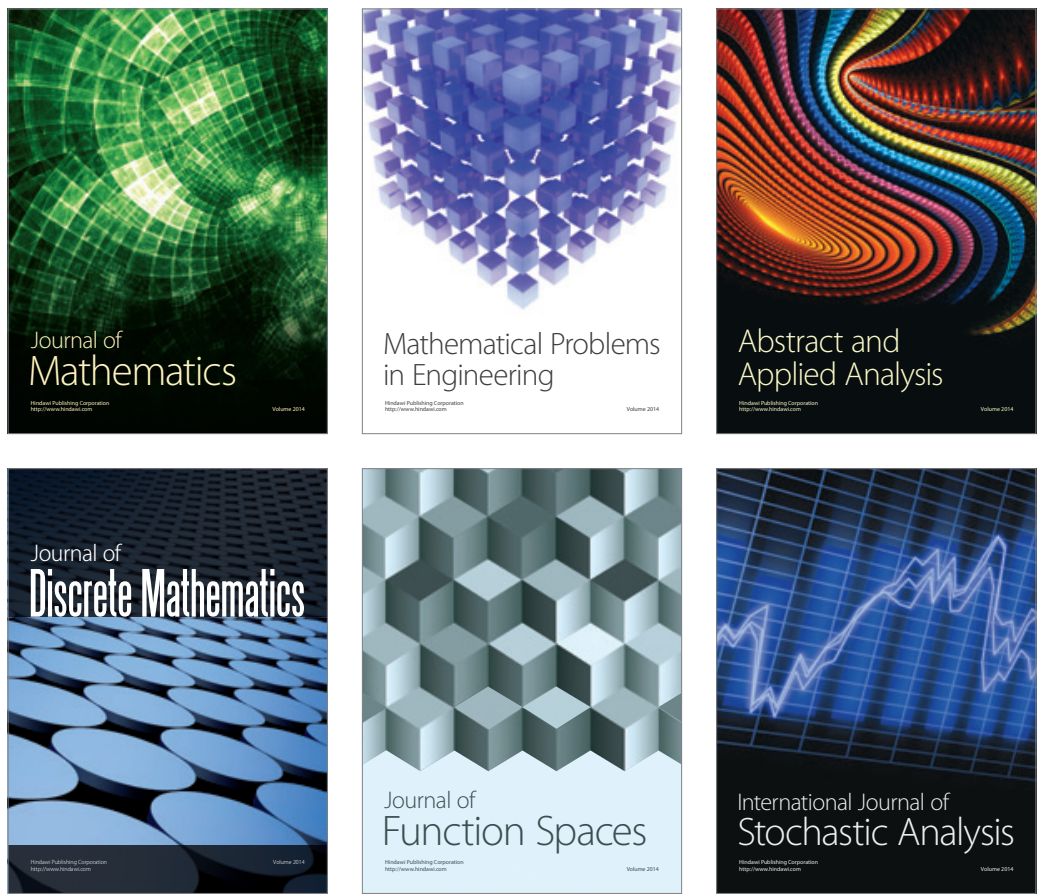

Journal of

Function Spaces

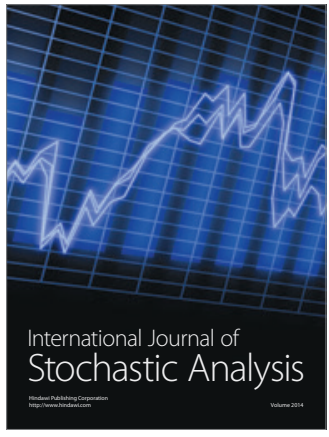

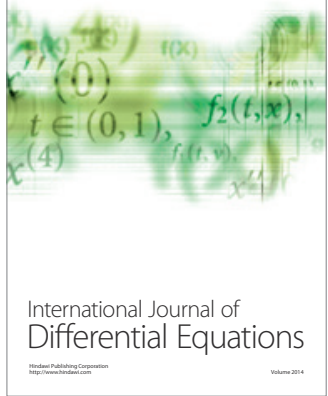
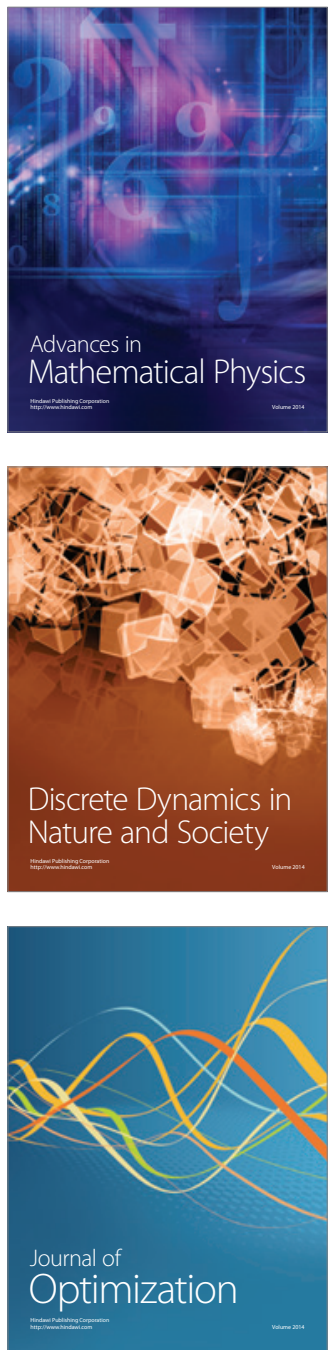